\title{
Synthesis and Characterization of a New Triphenylamine-Substituted PFO/PPV Copolymer
}

\author{
By Lingling GU, Jinrui BAI, Yu CHEN, ${ }^{*}$ and Ying LIN
}

The spiro-type bulky architecture in the polymer is intriguing since it can suppress the interchain interactions and enhance the photoluminescence efficiency. A new triphenylamine-substituted PFO/PPV alternating copolymer was synthesized by using a typical Heck-coupling reaction. This highly soluble polymer exhibits strong photoluminescence with maximum emission peaks centered at 417 and $441 \mathrm{~nm}$ in THF; 425 and $460 \mathrm{~nm}$ in benzonitrile. In deoxygenated dry benzonitrile, the fluorescence time profile of copolymer exhibited a bi-exponential decay with lifetime of $0.12 \mathrm{~ns}(98 \%)$ and $1.13 \mathrm{~ns}(2 \%)$. Upon excitation with nanosecond laser pulse at $355 \mathrm{~nm}$, the transient absorption band at $610 \mathrm{~nm}$ was observed.

KEY WORDS: Polyfluorene / Triphenylamine Functionality / Heck-Coupling Reaction /

As one of the useful hole transporting materials, triphenylamine (TPA) and its organic and polymeric derivatives have been widely used in organic and polymeric light-emitting diodes (LEDs) due to their low ionization potentials, tridimensional steric, and good UV-light harvesting properties. ${ }^{1}$ The biggest disadvantage of TPA lies in their crystallizaion, surface diffusion, relatively low thermal stability, and difficulties in fabricating devices as well. These drawbacks that restrict its applications in LEDs can be overcomed by covalently incorporating TPA into polymers by a variety of reactions as part of the main chain, at the end of side chain, as end groups, as branch points of star and as junctions of networks. For example, Giovanella et al. ${ }^{2}$ prepared a copolymer containing alternating fluorene and 9,9-bis-triphenylaminofluorene residues, in which TPA moiety can increase hole injection and transport. Using $\mathrm{FeCl}_{3}$ as an oxidant, Liou and his coworkers ${ }^{3}$ synthesized a mutlifunctional polymer for various optoelectronic device applications, poly[ $N, N^{\prime}$-diphenyl-4-methoxyphenylamine- $4^{\prime}, 4^{\prime \prime}$-diyl] (PMeOTPA), with blue light (435 nm) fluorescence quantum efficiency up to $79 \%$. Natera et al. ${ }^{4}$ preparated a new 9,9'-spirobifluorene-cored donor-acceptor bichromophore system in which TPA and carbazole (CBZ) moieties are used as the electron donor, and 1,3,4-oxadiazole (OXD) moieties as electron acceptor. The introduction of OXD units suppresses the delocalization of TPA radical cations effectively, allowing efficient electropolymerization through feasible TPA dimerization. The resulting polymer film exhibited reversible electrochemcial oxidation, accompanied by strong color changes with high coloration efficiency and contrast ratio, which could be switched through potential modulation. Two new conjugated polyfluorene derivatives (PDPF and PBPF) bearing triphenylamine moiety through a vinylene bridge have also been prepared. ${ }^{5}$ The maximum electroluminescence efficiency of the double-layer polymer light-emitting diodes (PLEDs) based on these two polymers was both about $2.08 \mathrm{~cd} / \mathrm{A}$. A thermally stabe polymer prepared from the polycodensation of $4,4^{\prime}$-dialdehyde- $4^{\prime \prime}-n$-butyl-triphenylamine with 1,4-bis(triphenylphosphonion-methyl)benzene dibromide ${ }^{6}$ exhibits a high fluorescence quantum efficiency of $94.3 \%$. Fang ${ }^{7}$ et al. reported an alternative copolymer comprising of fluorene and triphenylamine units with aldehyde group in the side chain, which showed good solubility in common organic solvents. Poly[4-phenyl-3,5-bi( $p$-vinylenephenyl)-1,2-4-triazole-alt-4,4-bi( $p$-vinylenephenyl)- $p$-2'-ethylhexyloxyphenylamine] (TAZ-TPA-PPV) ${ }^{8}$ has bright greenyellow emission, good solubility in some common organic solvents, excellent film-forming ability, and high thermal stability, and is of interest in photoluminescence applications. $\mathrm{Li}^{9}$ et al. syntheized a polythiophene derivative containing triphenylamine as side chains. The maximum power conversion efficiency of devices reached $0.45 \%$. The insertions of triphenylamine as side groups into polymer like polythiophene, ${ }^{10,11}$ polyethylene, ${ }^{12} \mathrm{PPV}^{13,14}$ etc. have also been reported.

The spiro-type bulky architecture in the polymer is intriguing since it can suppress the interchain interactions and enhance the photoluminescence efficiency. In our previous work, ${ }^{15}$ we designed and prepared a novel conjugated PFO/ PPV copolymer containing the pendant bis(4-alkoxyphenyl) groups in the C-9 position of every fluorene unit (Figure 1) through a typical Heck-couping reaction. The facile functionalization at the C-9 position of the fluorene unit may offer an opportunity to reduce the interchain interactions thereby improving the optoelectronic properties of the resulting polymers. The resulting polymer exhibits very strong photoluminescence with maximum emission peaks centered at $474 \mathrm{~nm}$ in dilute benzonitrle, and a single glass-transition temperature at about $95^{\circ} \mathrm{C}$. The fluorescence of the thin-film spin-coated onto ITO substrate was almost completely quenched. The main absorption peak in the UV-vis absorption spectrum is located at $427 \mathrm{~nm}$, followed by a shoulder peak at $450 \mathrm{~nm}$. The excited triplet-state maximum of polymer occurs

Key Lab for Advanced Materials, Department of Chemistry, East China University of Science and Technology, 130 Meilong Road, Shanghai 200237, People's Republic of China

*To whom correspondence should be addressed (Tel: +86-21-64253135, Fax: +86-21-64252485, E-mail: advmaterials@yahoo.com). 

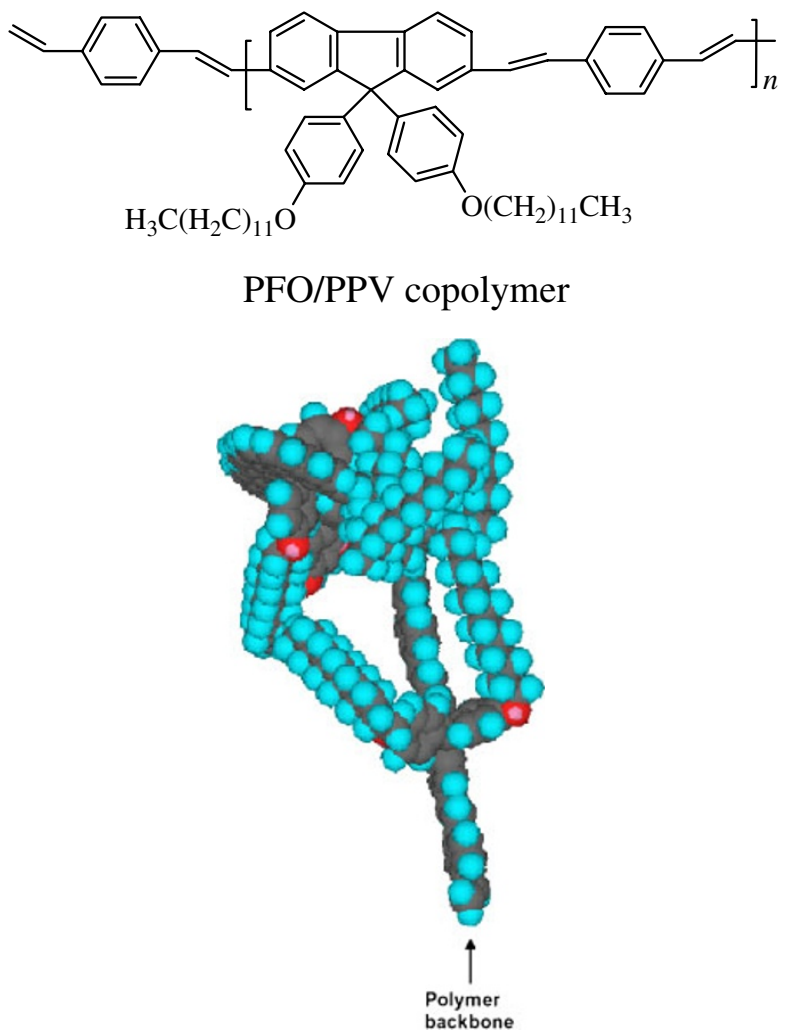

Figure 1. Molecular (top) and optimizied (down) Structures of the PFO/PPV copolymer.

in the region of $460-540 \mathrm{~nm}$ with a lifetime of $65.8 \mu \mathrm{s}$. The stable electroluminescent spectrum of the PLED device with configuration of ITO/Au/polymer $\mathrm{PFO} / \mathrm{PPV} / \mathrm{LiF} / \mathrm{Al}$ was obtained with a peak wavelength of $515 \mathrm{~nm}$. The stacking of the polymer chains in the solid state is responsible for the observed green electroluminescence. Although preliminary tests yielded relatively low performance devices, future devices using an optimized multilayer structure are expected to result in much higher external quantum efficiencies. To further impove the hole-transporting performance, and to suppress the possible formation of excimers in the solid state, we introduce bulky hole-transporting TPA groups, instead of 4-dodecyloxy functionality, to the C-9 position of fluorene, as shown in Scheme 1. It would be expected that the use of an extended 9,9-bis[4-( $N, N^{\prime}$-diphenylamino)phenyl]fluorenyl core in the polymerization reactions can give rise to a more efficient shielding effect on the polyfluorene main chain, which would suppress the formation of aggregates/excimers. ${ }^{16}$

\section{EXPERIMENTAL}

\section{General}

The operations for synthesis prior to the termination reaction were carried out under purified argon. 1,4-Divinylbenzene (95\%), palladium(II) acetate $(99.9 \%)$, tri-otolylphosphine (97\%), tributylamine (98.5\%), and copper(I) iodide (98\%) were purchased from Aldrich, and used without further

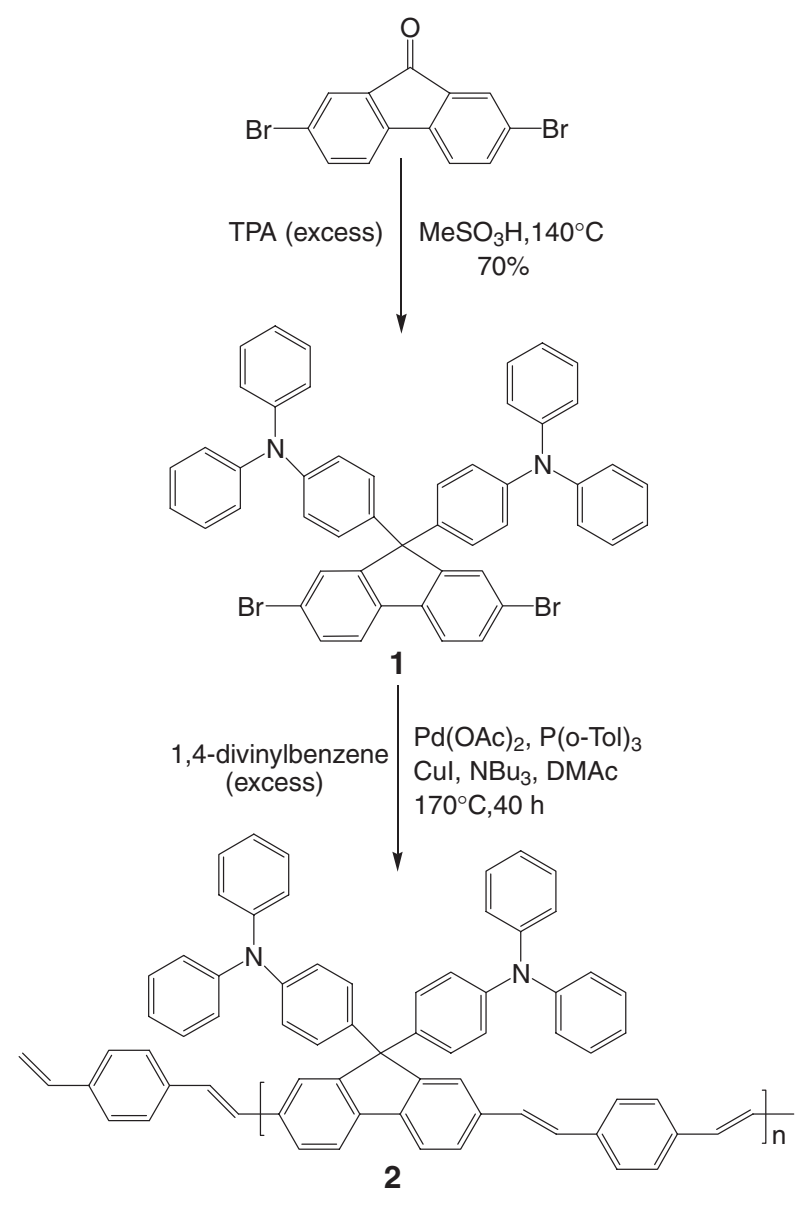

Scheme 1. Synthesis of the TPA-PFO/PPV copolymer.

purification. Organic solvents were purified, dried and distilled under dry nitrogen. IR spectra were recorded on a Nicolet Nagma-IR 550 spectrophotometer using KBr pellets. The UVvis absorption spectral measurements were carried out with a Shimadzu UV-2450 spectrophotometer. Thermal properties of the samples were measured using a Perkin-Elmer Pyris 1 thermogravimetric analyzer in flowing $\left(100 \mathrm{~mL} \cdot \mathrm{min}^{-1}\right)$ nitrogen. ${ }^{1} \mathrm{H}$ NMR spectra were performed on a JEOL LAMBDA $400\left(\mathrm{CDCl}_{3}\right.$ as solvent); Analytical thin layer chromatography (TLC) was performed using aluminium coated Merck Kiesegel 60254 plates.

Steady-state fluorescence spectra were measured on a Shimadzu RF-5300 PC spectrofluorophotometer equipped with a photomultiplier tube having high sensitivity in the 700$800 \mathrm{~nm}$ region. Fluorescence lifetimes were measured by a single-photon counting method using an argon ion laser, a pumped Ti:sapphire laser (Spectra-Physics, Tsunami 3960, fwhm $150 \mathrm{fs}$ ) with a pulse selector (Spectra-Physics, 3980), a second harmonic generator (Spectra-Physics, GWU-23PS), and a streakscope (Hamamatsu Photonics, C4334-01). The sample for the fluorescence measurement was dissolved in the dry THF or benzonitrile, filtered, transferred to a long quartz cell, and then capped and bubbled with high pure argon (without $\mathrm{O}_{2}$ and moisture) for at least $15 \mathrm{~min}$ before measurement. GPC was 
measured on a Waters chromatography unit interfaced to a Water 410 differential refractomter using THF as the eluent, linear polystyrene as standard.

The nanosecond transient absorption measurements in the near-IR region were measured by means of laser-flash photolysis; $355 \mathrm{~nm}$ light from a Nd:YAG laser (SpectraPhysics and Quanta-Ray GCR-130, 6 ns fwhm) was used as an excitation source. For transient absorption spectra in the nearIR region (600-1600 nm), monitoring light from a pulsed Xe-lamp was detected with Ge-avalanche photodiode module (Hamamatsu Photonics). All the samples in a quartz cell $(1 \times 1 \mathrm{~cm})$ were deaerated by argon bubbling through the solution for $20 \mathrm{~min}$.

\section{Synthesis of (9,9-bis[4-( $N, N$-diphenylamino)phenyl]-2,7-di- bromofluorene (1)}

To a stirred mixture of 2,7-dibromofluorenone (1.72 g, $5.09 \mathrm{mmol})$ and triphenylamine $(17.5 \mathrm{~g}, 71.34 \mathrm{mmol})$ was added methane sulfonic acid $(0.49 \mathrm{~g}, 5.10 \mathrm{mmol})$ under a purifed argon atmosphere, and then reacted at $140{ }^{\circ} \mathrm{C}$ for $6 \mathrm{~h}$. After cooling to the room temperature, the dichloromethane extract was washed with $\mathrm{Na}_{2} \mathrm{CO}_{3}$ solution until the aqueous layer reached neutral, and then dried over anhydrous $\mathrm{MgSO}_{4}$ and filtered. Evaporation of the solvent was followed by column chromatography $\left(\mathrm{SiO}_{2} /\right.$ hexane- $\left.\mathrm{CH}_{2} \mathrm{Cl}_{2}\right)$. The obtained product was recrystallized from acetone to give the TPAsubstituted 2,7-dibromofluorene $(2.95 \mathrm{~g}, 70 \%)$. FDMS: $m / z=811[\mathrm{M}+]$; UV-vis (in $\mathrm{CHCl3}$ ): $\lambda / \mathrm{nm}=256,310$, 322; ${ }^{1} \mathrm{H} \mathrm{NMR} \mathrm{(in} \mathrm{CDCl}_{3}$ ): $\delta / \mathrm{ppm}=6.99(\mathrm{~m}, 20 \mathrm{H}$, aryl $\mathrm{H}$ ), 7.22(m,8H, aryl H), 7.46(dd,2H), 7.51(d,2H), 7.56(d,2H).

\section{Synthesis of TPA-PFO/PPV Copolymer (2)}

1,4-Divinylbenzene $(4.94 \mathrm{mmol})$, palladium(II) acetate $(0.38 \mathrm{mmol})$, tri-otolylphosphine $(1.51 \mathrm{mmol})$, tributylamine (51.2 mmol), copper(I) iodide $(0.06 \mathrm{mmol})$, and anhydrous $N, N^{\prime}$-dimethylacetamide $(20 \mathrm{~mL})$ were added into a roundbottom flask containing 9,9-bis $\left(N, N^{\prime}\right.$-diphenylbenzenamine)2,7-dibromofluorene $(2.47 \mathrm{mmol})$ under highly purified nitrogen. The flask was fitted with a condenser and heated at $170{ }^{\circ} \mathrm{C}$ for 40 hours under static nitrogen. The reaction mixture was then poured into methanol $(300 \mathrm{~mL})$ with vigorously stirring. After addition, stirring continued in the absence of light for $24 \mathrm{~h}$. The grey-blue precipitate was collected by filtration and transferred to a thimble, where the solids were being washed by methanol for $72 \mathrm{~h}$ to remove any soluble trapped impurities. After dryness, the obtained crude product was then transferred to a thimble again, eluted by THF for $72 \mathrm{~h}$. The eluate was collected, and the solvent THF evaporated under reduced pressure. About $50 \mathrm{mg}$ of soluble polymer material was obtained. UV-vis (in THF): $\lambda_{\max } / \mathrm{nm}=308$, 374. Photoluminescence (in benzonitrile): $\lambda_{\max } / \mathrm{nm}=416$ (shoulder), 441 ; (in THF): $\lambda_{\max } / \mathrm{nm}=424$ (shoulder), $460 ;{ }^{1} \mathrm{H}$ NMR: $\delta / \mathrm{ppm}=$ $6.89(-\mathrm{CH}=\mathrm{CH}-$ ),$\delta / \mathrm{ppm}=7.0-7.9$ (aromatic protons of fluorene, phenylene, TPA units in the polymer backbone); IR (KBr): $v / \mathrm{cm}^{-1}=2963(\mathrm{~ms}), 2923(\mathrm{~m}), 2851(\mathrm{w}), 1742$ (vw), 1592 (m), 1505 (m), 1493 (m), 1446 (vw), 1413 (vw), 1323 (w), 1262 (vs), 1096 (vs), 1023 (vs), 864 (m), 803 (vs), 752 (m), $697(\mathrm{~m}), 635(\mathrm{vw}), 618(\mathrm{vw}), 542(\mathrm{vw}), 526(\mathrm{w}), 506(\mathrm{w})$; GPC: $M_{\mathrm{n}}=2.50 \times 10^{4}, M_{\mathrm{w}}=5.31 \times 10^{4}, \mathrm{Pd}=2.12$.

\section{RESULTS AND DISCUSSION}

Condensation of 2,7-dibromo-9-fluorenone with a large excess of triphenylamine at $140^{\circ} \mathrm{C}$ yields 9,9-bis(4-diphenylaminophenyl)-2,7-dibromofluorene (1) in the presence of methane sulfonic acid. The Heck-coupling reaction of $\mathbf{1}$ and 1,4-divinylbenzene produces a TPA-PFO/PPV alternative copolymer (2) with a relatively high molecular weight. This polymer is highly soluble in some common organic solvents such as THF, $\mathrm{CHCl}_{3}$ and others, and by GPC analysis against a linear polystyrene standard was found to have $M_{\mathrm{w}}$ of $5.31 \times 10^{4}$, and a polydispersity of 2.12 . The ${ }^{1} \mathrm{H} \mathrm{NMR}$ spectrum of 2 in $\mathrm{CDCl}_{3}$ is consistent with the expected structure of the TPA-PFO/PPV alternative copolymer. Generally, in polycondensation reactions, the stoichiometry of the fed amounts of the two monomers should directly affect the degree of polymerization. In our polymerization reaction we employed two-fold excess of the 1,4-divinylbenzene monomer in an attempt to completely remove any residual bromine functionalities that might act as fluorescence quenching sites, which is generally undesirable for the improvement of the PLED performance.

A typical Heck coupling reaction, i.e., $\mathrm{Pd}(0)$-mediated coupling of an aryl or vinyl halide or sulfonate with an alkene under basic conditions, was based on an aryl iodide or bromide as the electrophilic partner and a terminal alkene as the nucleophilic partner. ${ }^{17}$ This kind of coupling reaction has been found to be very versatile and applicable to a wide range of aryl species and a diverse range of olefins. ${ }^{17 a}$ Basically olefins with electron-withdrawing groups can give better yields. Aryl bromides with electron-donating substituents were particularly sluggish in their reactivity when compared to these with electron-withdrawing substituents. In our case, the monomer 9,9-bis(4-diphenylaminophenyl)-2,7-dibromofluorene contains two units of the electron-donating triphenylamines (TPA) at the C-9 position of the fluorene unit, while another monomer 1,4divinylbenzene has no any electron-withdrawing groups. Based on these reasons the resultant polymer 2 was obtained in extremely low yield. In addition, both vinyl moieties in 1,4divinylbenzene are equally reactive and therefore polymerization of itself results in the formation of a hyperbranced crosslinked polymer. ${ }^{18}$ As a matter of fact, in our polymerization reaction, some insoluble polymeric materials were indeed observed.

When polyfluorene-based materials were incorporated into light-emitting devices, the aggregate formation, which usually resulted in a loss of the pure blue color emission, and a longer wavelength emission, could be easily observed. This aggregation effect, i.e., $\pi-\pi$ stacking effect, among the polymer chains, is usually depicted as a coplanar association of aromatic rings and is driven by enhanced van der Waal's attractive forces between polymer chains. The tendency to aggregation is 


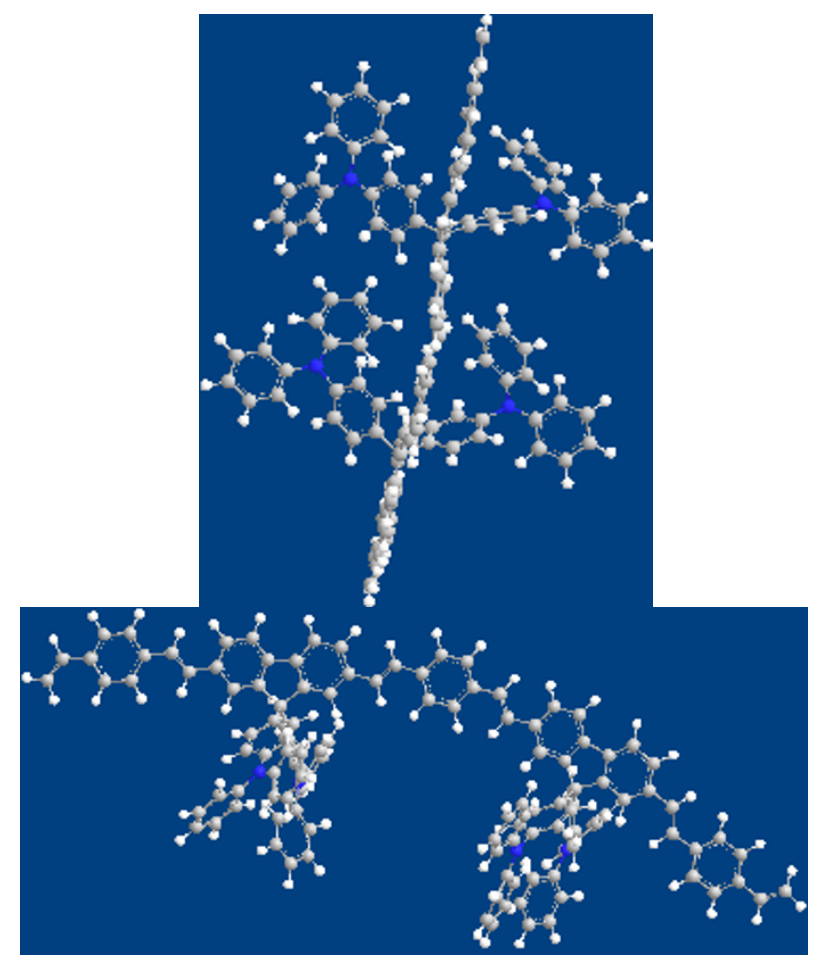

Figure 2. Optimized structure of the TPA-PFO/PPV copolymer.

mainly dependent on the structural characteristics of the polymers. One way to effectively prevent the formation of aggregates is attach the very bulky sidegroups to the C-9 position of the fluorene units. Another two approaches to hinder aggreagte formaton have also been reported in the literatures: (a) incorporation of polyfluorenes into a three dimensional network; and (b) preparation of polyfluorenebased copolymers with a spiro-fluorene core. ${ }^{19}$ To gain insights into the molecular structure and to examine the suppression of $\pi-\pi$ stacking among the polymer chains, optimized structure of 2 was calculated by HF/3-21G level using Gaussian-98 package. From Figure 2, one can clearly see that in the optimized structure the pendant two bulky TPA moieties at the C-9 position of the fluorene unit are located on both sides of the plane of the polymer backbone, respectively, which would lead to effectively suppression of $\pi-\pi$ stacking among the polymer chains due to their strong steric hindrance, and consequently to an enhancement of the solubility of polymer in some common organic solvents.

The thermal property of $\mathbf{2}$ was evaluated by TG analysis (Figure 3). The sample was heated to $500^{\circ} \mathrm{C}$ in flowing $\left(100 \mathrm{~mL} \cdot \mathrm{min}^{-1}\right)$ dry nitrogen atmosphere. The weight loss of the polymer was less than $10 \%$ until upon heating to $300^{\circ} \mathrm{C}$; its onset temperature for the thermal bond cleavage is at $178^{\circ} \mathrm{C}$. In contrast to the polymer 2, the TGA thermogram of the PFO/ PPV alternative copolymer ${ }^{15}$ exhibits two weight-loss plateaus. At lower temperatures almost no weight loss was observed. The 4-dodecyloxy-side chain in copolymer decomposed first at $160-320^{\circ} \mathrm{C}$, its onset temperature for the thermal bond cleavage is at $210^{\circ} \mathrm{C}$. Then the polymer backbone was

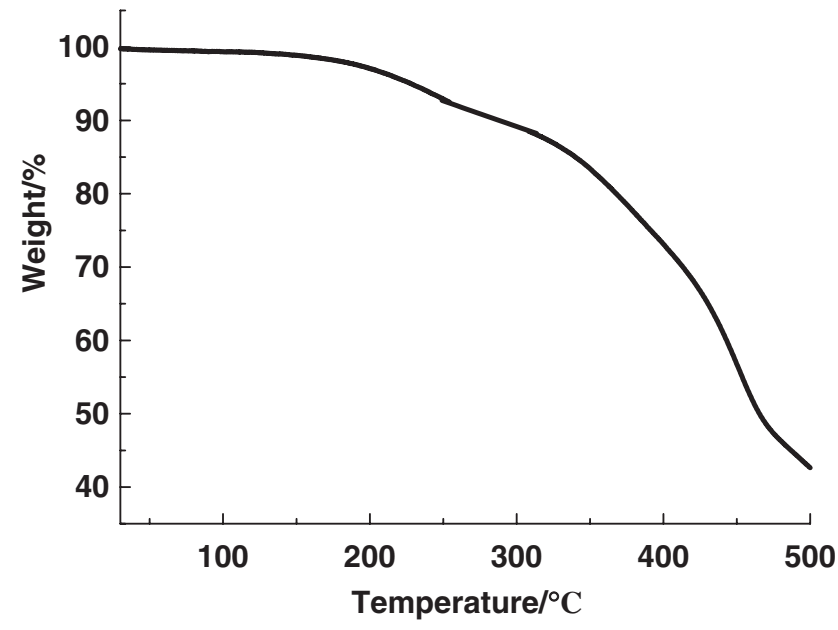

Figure 3. TGA thermogram of the TPA-PFO/PPV copolymer measured in nitrogen atmosphere.

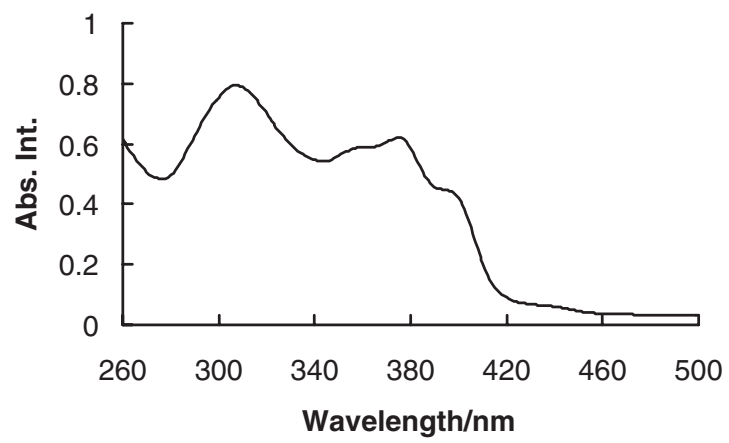

Figure 4. UV-vis absorption spectrum of the TPA-PFO/PPV copolymer in the dilute THF solution.

subjected to decomposition at $350-500{ }^{\circ} \mathrm{C}$, where the onset temperature for the thermal bond cleavage is at $404{ }^{\circ} \mathrm{C}$. These results showed that the thermal stability of the present polymer is not so high compared with the PFO/PPV alternative coloymer containing the pendant bis(4-alkoxyphenyl) groups in the C-9 position of every fluorene unit. This might be associated with the strong steric hindrance effect caused by the bulky TPA moieties in the conjugated system.

As shown in Figure 4, the UV-vis absorption spectra consist of the approximate superposition of the absorption features of their constitutive units (i.e., the conjugated polymer backbone and the pendant TPA units). The main absorption peaks in the UV-vis absorption spectrum of $\mathbf{2}$ are located at 308, 356(shoulder), 374 and 796(shoulder) $\mathrm{nm}$. The peaks at 308 and $374 \mathrm{~nm}$ are assigned to $\mathrm{n}-\pi^{*}$ absorption of the triphenylamine moiety, ${ }^{20}$ and the $\pi-\pi^{*}$ transition of the polymer backbone, ${ }^{14,21}$ respectively.

The fluorescence measurements of $\mathbf{2}$ were carried out in benzonitrile and THF, respectively, by applying $355 \mathrm{~nm}$ as excitation wavelength (Figure 5). As expected, the polymer 2 exhibits strong photoluminescence with maximum emission peaks centered at 417 and $441 \mathrm{~nm}$ in THF; 425 and $460 \mathrm{~nm}$ in benzonitrile. Changing the solvent from THF to a more polar 


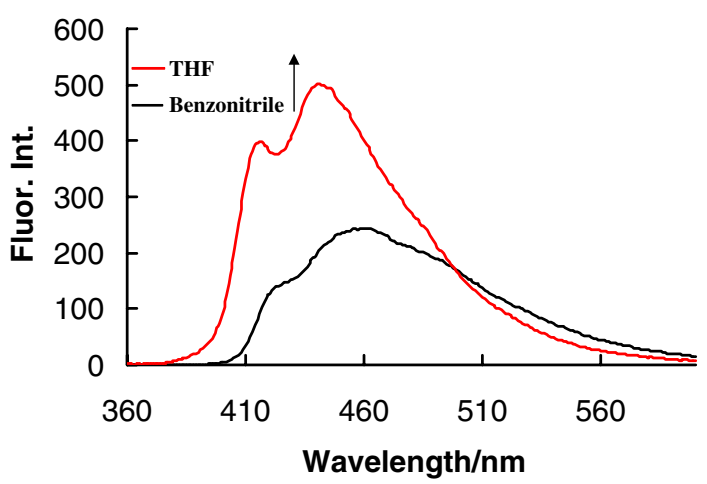

Figure 5. Steady-state fluorescence spectra of the TPA-PFO/PPV copolymer in THF and benzonitrile. $\lambda_{\mathrm{ex}}=355 \mathrm{~nm}$.

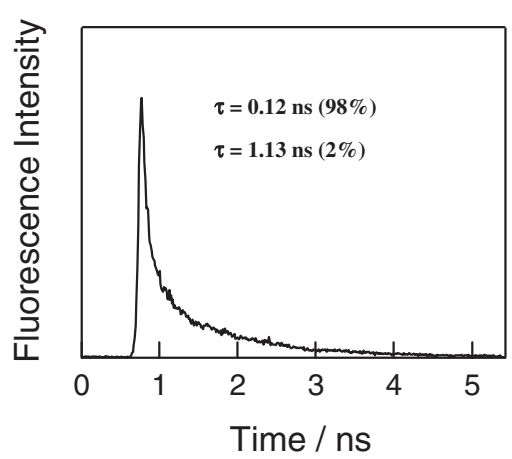

Figure 6. Fluorescence time profile of the TPA-PFO/PPV copolymer in benzonitrile at $460 \mathrm{~nm}\left(\lambda_{\mathrm{ex}}=355 \mathrm{~nm}\right)$.

benzonitrile resulted in a red-shift of $\Delta \lambda=19 \mathrm{~nm}$ of the maximum emission peak at $441 \mathrm{~nm}$, and in the decrease of the photoluminescence intensity due to the electron-withdrawing effect of the benzonitrile molecules, suggesting intermolecular quenching from 2 to cyano-group of benzonitrile. In deoxygenated dry benzonitrile, as shown in Figure 6, the fluorescence time profile of $\mathbf{2}$ exhibited a bi-exponential decay. From the initial fast decay part of 2 , lifetime $\left(\tau_{\mathrm{f} 1}\right)$ of the single excited state is $0.12 \mathrm{~ns}$ (fraction of this component: $98 \%$ ). From the slow decay part of $\mathbf{2}$, the lifetime $\left(\tau_{\mathrm{f} 2}\right)$ of another singlet excited state is $1.13 \mathrm{~ns}$ (fraction of this component: $2 \%$ ). The value of the latter is close to the fluorescence lifetime of typical PPV polymer (about $1.27 \mathrm{~ns}$ ). As comparison, for the PFO/ PPV alternative copolymer reported in our previous work, ${ }^{15}$ the fluorescence decay monitored at $474 \mathrm{~nm}\left(\lambda_{\mathrm{ex}}=410 \mathrm{~nm}\right)$ in the same solvent shows two exponential-decay processes too. The excitation-wavelength dependence of the steady-state fluorescence spectrum of $\mathbf{2}$ was observed in THF solution (Figure 7). Upon excitation with $390 \mathrm{~nm}$ laser, the maximum photoluminescence emission intensity exhibited by the sample was detected.

The nanosecond transient absorption technique has been performed to monitor the photophysical process by applying $355 \mathrm{~nm}$ with $6 \mathrm{~ns}$ laser pulse. The transient absorption spectrum of 2 (Figure 8) obtained in argon-saturated anhydrous benzonitrile shows a transient absorption band appeared at $c a$.

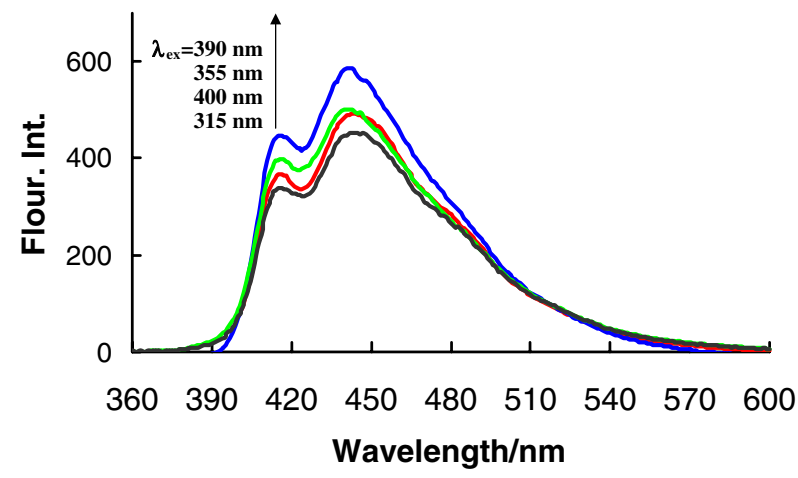

Figure 7. Photoluminescence spectra of the TPA-PFO/PPV copolymer in THF at different excitation-wavelengths.
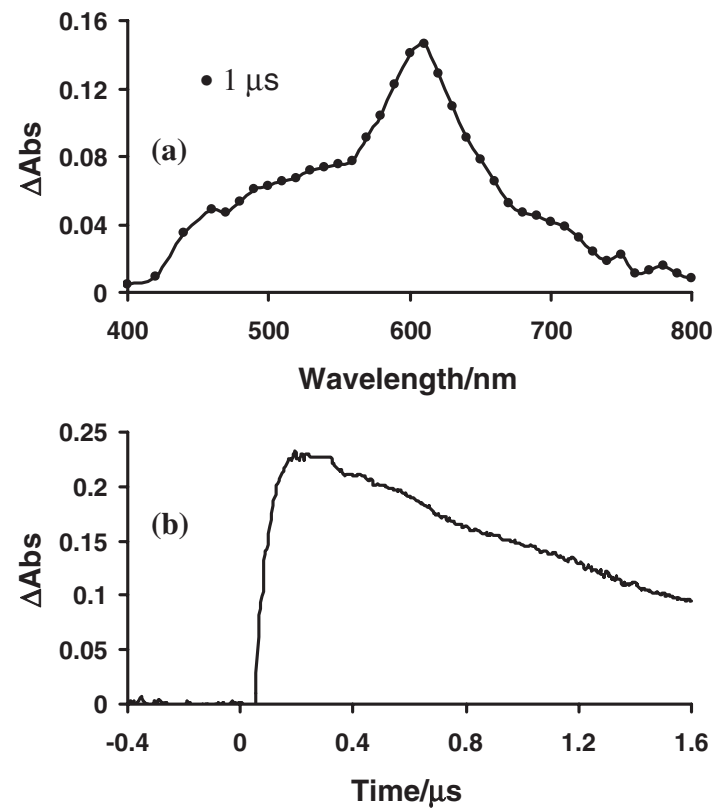

Figure 8. (a) Transient absorption spectrum and (b) time profile at $610 \mathrm{~nm}$ of the TPA-PFO/PPV copolymer in argon-saturated benzonitrile $(0.1 \mathrm{mM}) . \lambda_{\mathrm{ex}}=355 \mathrm{~nm}$

$610 \mathrm{~nm}$ due to the excited triplet state ${ }^{3}$ (TPA-PFO/PPV)*. On addition of $\mathrm{O}_{2}$, the transient absorption band at $610 \mathrm{~nm}$ disappeared, suggesting that the energy transfer takes place from the triplet excited state of $\mathbf{2}$ to $\mathrm{O}_{2}$, yielding probably ${ }^{1} \mathrm{O}_{2}$. In the absence of $\mathrm{O}_{2}$, the slow decay rates depend on the laser powers, suggesting the intermolecular triplet-triplet annihilation is due to the collision between the highly concentrated triplet states.

\section{CONCLUSION}

By using a typical Heck-coupling reaction, a new $\pi$ conjugated TPA-PFO/PPV alternating copolymer containing the pendant bis(4-( $N, N^{\prime}$-diphenylamino)phenyl groups in the C-9 position of every fluorene unit was prepared. Introduction of 4-4-( $N, N^{\prime}$-diphenylamino)phenyl functionality to the C-9 position of fluorene could effectively suppress $\pi-\pi$ stacking 
among the polymer chains, and consequently enhance the solubility of polymer in some common organic solvents. The thermal stability of the present polymer is not so high compared with other conjugated polymers due to the introduced strong steric hindrance from the bulky TPA moieties in the conjugated system. In deoxygenated dry benzonitrile, the fluorescence time profile of TPA-PFO/PPV copolymer exhibited a bi-exponential decay with lifetime of $0.12 \mathrm{~ns}(98 \%)$ and $1.13 \mathrm{~ns}(2 \%)$. Upon excitation with nanosecond laser pulse at $355 \mathrm{~nm}$, the transient absorption band at $610 \mathrm{~nm}$ was observed.

Acknowledgment. We are grateful for the financial support of National Natural Science Foundation of China (20676034, 20876046), Ministry of Education of China (309013), Shanghai Municipal Educational Commission for the Shuguang fellowship (08GG10) and Shanghai Eastern Scholarship, respectively.

Received: April 22, 2009

Accepted: July 2, 2009

Published: August 19, 2009

\section{REFERENCES}

1. a) H. Y. Lin, G. S. Liou, W. Y. Lee, and W. C. Chen, J. Polym. Sci., Part A: Polym. Chem., 45, 1727 (2007).

b) C. Ego, A. C. Grimsdale, F. Uckert, G. Yu, G. Srdanov, and K. Müllen, Adv. Mater., 14, 809 (2002).

c) Q. Fang and T. Tamamoto, Macromolecules, 37, 5894 (2004).

d) C. H. Chen, J. Shi, and C. W. Tang, Macromol. Symp., 125, 1 (1997).

e) J. H. Park, N. S. Cho, K. J. Young, H. J. Cho, H. K. Shim, H. Kim, and Y. S. Lee, Org. Electron., 8, 272 (2007).

2. U. Giovanella, M. Pasini, S. Destri, W. Porzio, and C. Botta, Synth. Met., 158, 113 (2008).

3. G. S. Liou, Y. L. Yang, W. C. Chen, and O. Y. Su, J. Polym. Sci., Part A: Polym. Chem., 45, 3292 (2007).
4. J. Natera, L. Otero, L. Sereno, F. Fungo, N. S. Wang, Y. M. Yeun, T. Y. Hwu, and K. T. Wong, Macromolecules, 40, 4456 (2007).

5. R. Tang, Z. Tan, Y. Li, and F. Xi, Chem. Mater., 18, 1053 (2006).

6. Y. L. Liu, Y. R. Xin, J. H. Li, G. X. Zhao, B. X. Ye, S. G. Xu, and S. K. Cao, React. Funct. Polym., 67, 253 (2007).

7. Q. Fang and T. Yamamoto, Macromolecules, 37, 5894 (2004).

8. Z. Liu, Y. Zhang, Y. Hu, G. Su, D. Ma, L. Wang, X. Jing, and F. Wang, J. Polym. Sci., Part A: Polym. Chem., 40, 1122 (2002).

9. Y. W. Li, L. L. Xue, H. J. Xia, B. Xu, S. P. Wen, and W. J. Tian, J. Polym. Sci., Part A: Polym. Chem., 46, 3970 (2008).

10. G. Y. Sang, E. J. Zhou, Y. Huang, Y. P. Zou, G. J. Zhao, and Y. F. Li, J. Phys. Chem. C, 113, 5879 (2009).

11. Y. P. Zou, G. Y. Sang, W. P. Wu, Y. Q. Liu, and Y. F. Li, Synth. Met., 159, 182 (2009).

12. M. H. Park, J. O. Huh, Y. Do, and H. M. Lee, J. Polym. Sci., Part A: Polym. Chem., 46, 5816 (2008).

13. P. Shen, G. Y. Sang, J. J. Lu, B. Zhao, M. X. Wan, Y. P. Zou, Y. F. Li, and S. T. Tan, Macromolecules, 41, 5716 (2008).

14. Z. A. Tan, R. P. Tang, F. Xi, and Y. F. Li, Polym. Adv. Technol., 18, 963 (2007).

15. Y. Chen, Y. Araki, J. Doyle, A. Strevens, O. Ito, and W. J. Blau, Chem. Mater., 17, 1661 (2005).

16. a) D. Marsitzky, R. Vestberg, P. Blainey, B. T. Tang, C. J. Hawker, and K. R. Carter, J. Am. Chem. Soc., 123, 6965 (2001).

b) C. H. Chou and C. F. Shu, Macromolecules, 35, 9673 (2002).

17. a) F. Alonso, I. P. Beletskaya, and M. Yus, Tetrahedron, 61, 11771 (2005).

b) G. T. Crisp, Chem. Soc. Rev., 27, 427 (1998).

18. a) L. Jafarpour and S. P. Nolan, Org. Lett., 2, 4075 (2000).

b) T. Uemura, D. Hiramatsu, Y. Kubota, M. Takata, and S. Kitagawa, Angew. Chem., Int. Ed., 46, 4987 (2007).

c) H. Staudinger, Trans. Faraday Soc., 32, 323 (1936).

19. P. Herguth, Ph. D. Thesis, USA, 2003.

20. a) Y. Chen, Y. Lin, M. E. Ei-Khouly, N. He, A. X. Yan, Y. Liu, L. Z. Cai, and O. Ito, J. Polym. Sci., Part A: Polym. Chem., 46, 4249 (2008).

b) A. Bolognesi, P. Betti, C. Botta, S. Destri, U. Giovanella, J. Moreau, M. Pasini, and W. Porzio, Macromolecules, 42, 1107 (2009). c) J. J. Lu, P. Shen, B. Zhao, B. Yao, Z. Y. Xie, E. H. Liu, and S. T. Tan, Eur. Polym. J., 44, 2348 (2008).

21. M. E. El-Khouly, Spectrochim. Acta, Part A, 67, 636 (2007). 